\title{
Intercellular Adhesion Molecule Measurement
}

National Cancer Institute

\section{Source}

National Cancer Institute. Intercellular Adhesion Molecule Measurement. NCI Thesaurus. Code C124344.

The determination of the amount of intercellular adhesion molecule present in a sample. 